\title{
ANALYSIS OF THE STATION NO. 2 SEISMOSCOPE RECORD- 1966, PARKFIELD, CALIFORNIA, EARTHQUAKE
}

\author{
By M. D. Trifunac and D. E. Hudson
}

\section{ABSTRACT}

\begin{abstract}
During the 1966 Parkfield, California, earthquake a strong motion accelerograph and an adjacent seismoscope were located essentially at the causative fault. The accelerograph component parallel to the fault malfunctioned and left no recorded trace. The seismoscope record and the component of the ground motion perpendicular to the fault are used to reconstruct the acceleration component in the direction parallel to the fault. The details of the derived acceleration parallel to the fault differ from the past recorded strong ground motions in that higher frequency components are present. The peak ground accelerations transverse and along the fault are found to be of the same order of magnitude.
\end{abstract}

\section{INTRODUCTION}

The Parkfield earthquake of June 27, 1966, magnitude 5.6, proved to be of considerable importance for studies of strong earthquake ground motion. It had a more extensive strong motion instrumental coverage than any other previously recorded earthquake. The instrumentation consisted of an array of five strong motion accelerographs and sixteen seismoscopes, which were distributed along a 10 mile line perpendicular to the San Andreas Fault (Fig. 1). A description of accelerograph records (Cloud and Perez, 1967), seismoscope records (Hudson and Cloud, 1967), damage (Cloud, 1967), and an analysis of accelerograms (Housner and Trifunac, 1967) may be found in previous papers.

The character of the ground motion at Station 2 (Fig. 1) was described by Housner and Trifunac (1967). Station 2 was located some 280 feet southwest of observed surface cracking on the general line of the San Andreas Fault, and was equipped with one AR-240 strong motion accelerograph and one seismoscope. Unfortunately the accelerograph component parallel to the fault malfunctioned and no acceleration trace was obtained in this direction. The recorded ground motion perpendicular to the fault direction indicated a peak acceleration of 50 per cent of $g$ and was accompanied by a displacement pulse of approximately 10 inches and 1.5 seconds duration. This pulse occurred some four seconds after the accelerograph was triggered.

The first motions, up to about four seconds, were also well recorded by the seismoscope which was located adjacent to the AR-240 accelerograph (Figure 1). At about 4 seconds, the seismoscope needle went off scale, and dislodged the smoked glass plate so that no further record was obtained. This assisted the present analysis, since the later portion of the record was not present to complicate the picture.

This earthquake provided the first and so far the only opportunity to measure the character of strong earthquake ground motion at the fault, and it is important to extract the maximum amount of information from this data. It is the objective of this paper to derive information about the character of the motion parallel to the fault by combining the seismoscope record and the transverse acceleration trace. Although by this approach only approximately the first four seconds of motion can be reconstructed, it is believed that even this short part of the complete time history may prove to be useful. 


\section{Seismoscope Principles}

The theory and application of the seismoscope has been covered in earlier papers (Hudson, 1958; Cloud and Hudson, 1961; Hudson and Cloud, 1967).

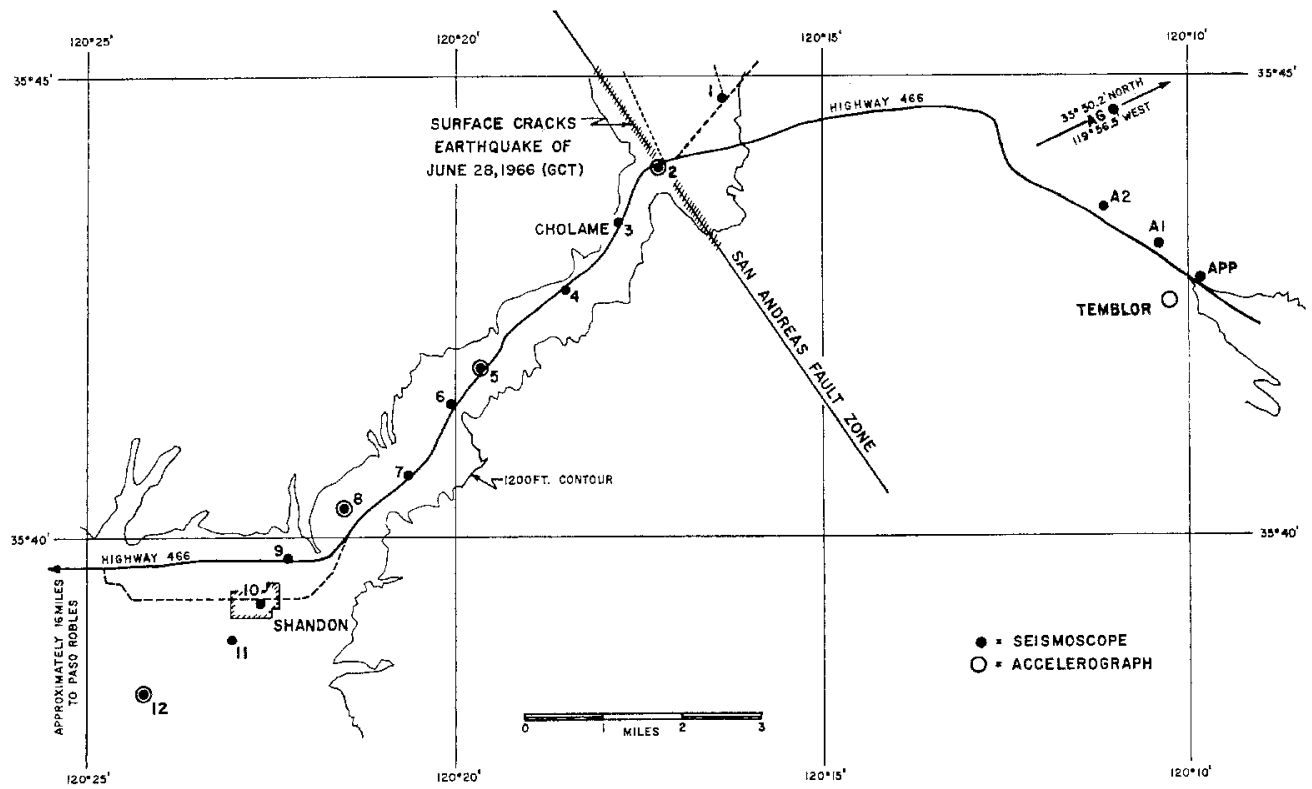

Fig. 1. Array map showing locations of accelerographs, seismoscopes and fault zone. Parkfield earthquake. (reprodueed from Hudson and Cloud 1967).

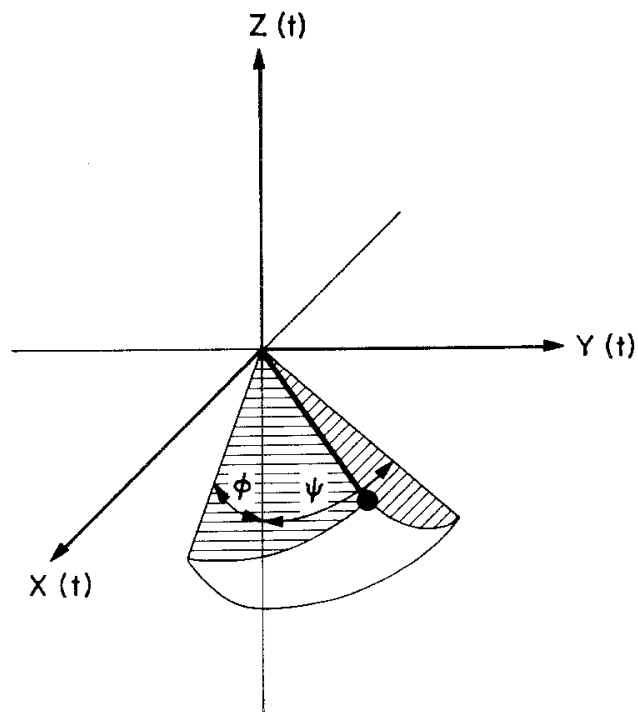

FIG. 2. Coordinates $\varphi$ and $\psi$ used in describing the relative seismoscope motion. The general motion of the seismoscope support is described by the general displacement $x(t), y(t), z(t)$.

Laboratory and field tests had shown the validity for the usual type of applications and simplifications such as the assumption of a constant equivalent viscous friction and the neglect of vertical accelerations. For the present purpose, it is desirable to make a somewhat more exact analysis of the instrument characteristics to ensure optimum accuracy in the interpretation. 
There are several seismoscope characteristics that should be considered in the description of the exact instrument response. Torsional vibrations, Coulomb type friction between the needle and the recording glass, and the effects of vertical accelerations should be treated. Laboratory tests have shown that the equivalent viscous damping decreases as amplitude on the recording glass increases. Shaking table tests and field tests indicate that torsional motions are small and do not appreciably influence the record.

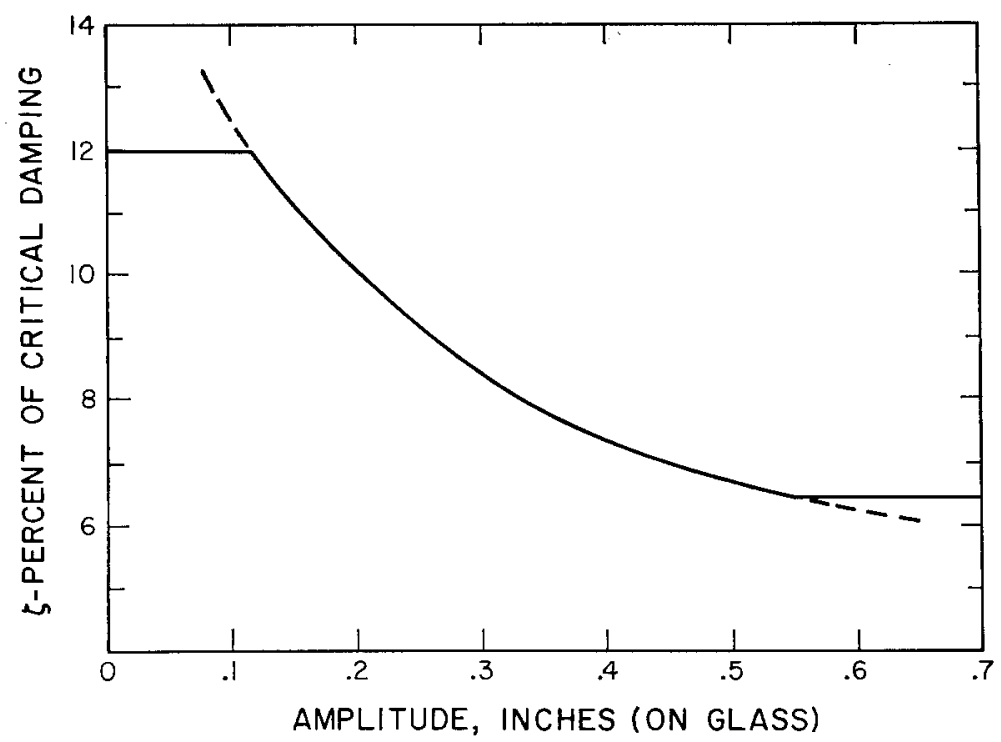

FIG. 3. Functional dependence of the fraction of the critical damping on the amplitude of the seismoscope response measured on the recording glass.

For the most general support motion, with the coordinate system as in Figure 2, the differential equations for small angles are:

$$
\begin{aligned}
& \ddot{\varphi}+2 \omega_{n} \zeta(A) \dot{\varphi}+{\omega_{n}}^{2} \varphi=-\frac{\omega_{n}{ }^{2}}{g}(\ddot{x}+\varphi \ddot{z}) \\
& \ddot{\psi}+2 \omega_{n} \zeta(A) \dot{\psi}+{\omega_{n}}^{2} \psi=-\frac{\omega_{n}{ }^{2}}{g}(\ddot{y}+\psi \ddot{z}) .
\end{aligned}
$$

In these equations small quantities of the second order have been neglected, as well as the effect of torsional motions. To correct for the additional Coulomb friction a fraction of critical damping is introduced (Figure 3) as a function of the amplitude of the response in accordance with the laboratory experiments (Hudson, 1958).

\section{Analysis of the Seismoscope Record at Station 2}

Stations 5 and 8 (Figure 1) were both equipped with AR-240 accelerographs and seismoscopes. This made it possible to calculate seismoscope responses using the ground acceleration as recorded by the accelerographs and to compare them with the recorded seismoscope responses (Hudson and Cloud, 1967, p. 1154, Figures 9 and 10). The excellent agreement obtained in this way using the uncoupled small angle equations inspired a considerable confidence in the details of the seismoscope record, and encouraged the present extended analysis. 
Equation (1b) was numerically integrated by taking $\ddot{y}(t)$ as the known acceleration recorded by the AR-240 at Station 2 in the N65E direction and $\ddot{z}(t)$ as the known vertical acceleration recorded on the vertical component of the same instrument (Housner and Trifunac, 1967). It was assumed that the damping $\zeta(A)$ is given as in Figure 3 . The natural frequency $\omega_{n}$ was measured in the field as $8.05 \mathrm{rad} / \mathrm{sec}$ (Cloud,

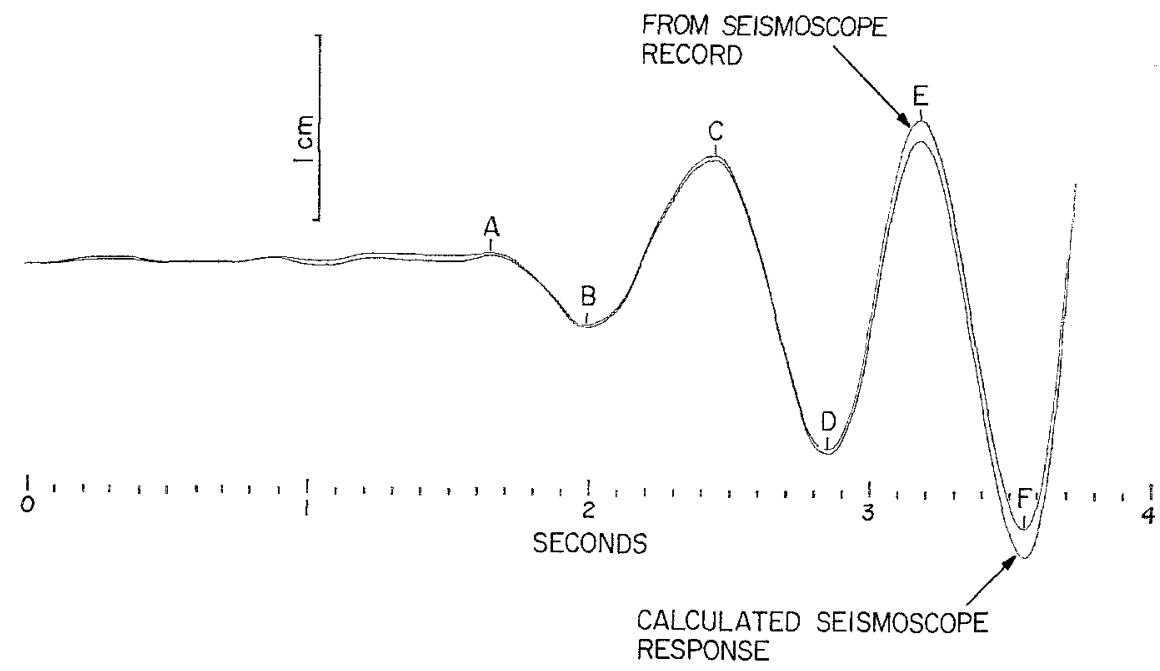

Fra. 4. Comparison of the displacement-time history for calculated and recorded seismoscope responses at Station 2 . The letters $A, B, \cdots$ refer to the points identified in Figure $5 b$.

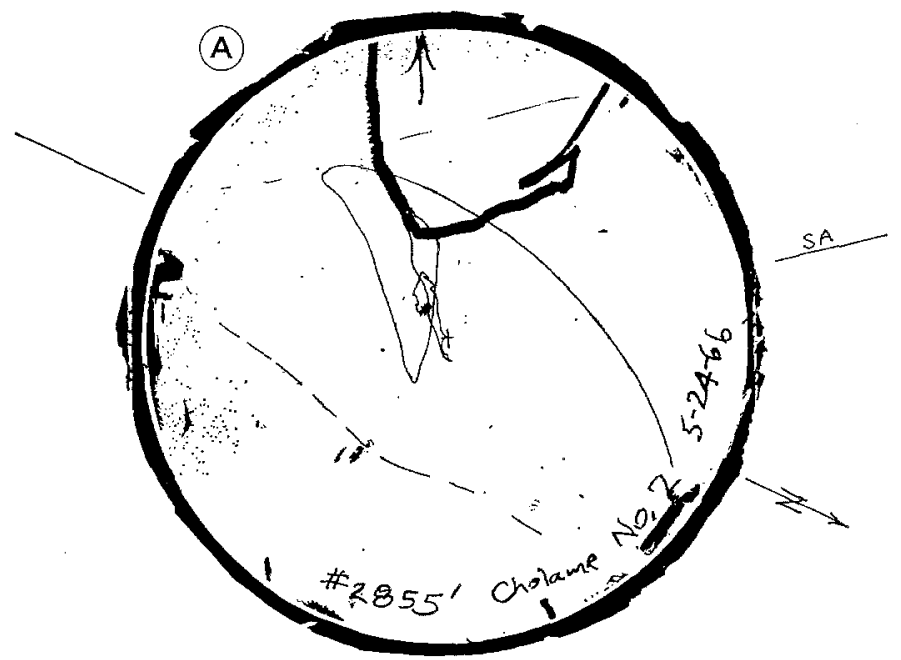

FIG. 5a. Seismoscope record at Station 2.

1966). Integration of equation (1b) was performed on an IBM 7094 using the AdamsMoulton predictor-corrector formulae and with time increments of .01 seconds. Starting values were obtained using the Runge-Kutta-Gill method. The resulting seismoscope response $\psi$ is plotted in Figure 4.

The seismoscope record in Figure $5 \mathrm{a}$ is a photograph of the original record plate showing approximately the first four seconds of the instrument response. Since the direction in which time is increasing is clearly evident, the digitized seismoscope record 
can be projected on the $y$ direction for which the seismoscope response has been calculated using equation (1b) (Figure 4). To accomplish this the digitized seismoscope record was divided into segments extending from one local extremum to another so that a one to one correspondence could be established with the equivalent segments between successive local extrema on the calculated response curve in Figure 4. By projecting each digitized seismoscope record point onto the corresponding branch of the calculated seismoscope response, time coordinates can be established for all digitized data points from Figure 5a. This simple procedure requires some care because none of the peak to peak amplitudes of the calculated and recorded response agree exactly. However, after minor rescaling of the peak amplitudes during the interpolation procedure, time coordinates can be determined with a satisfactory accuracy and

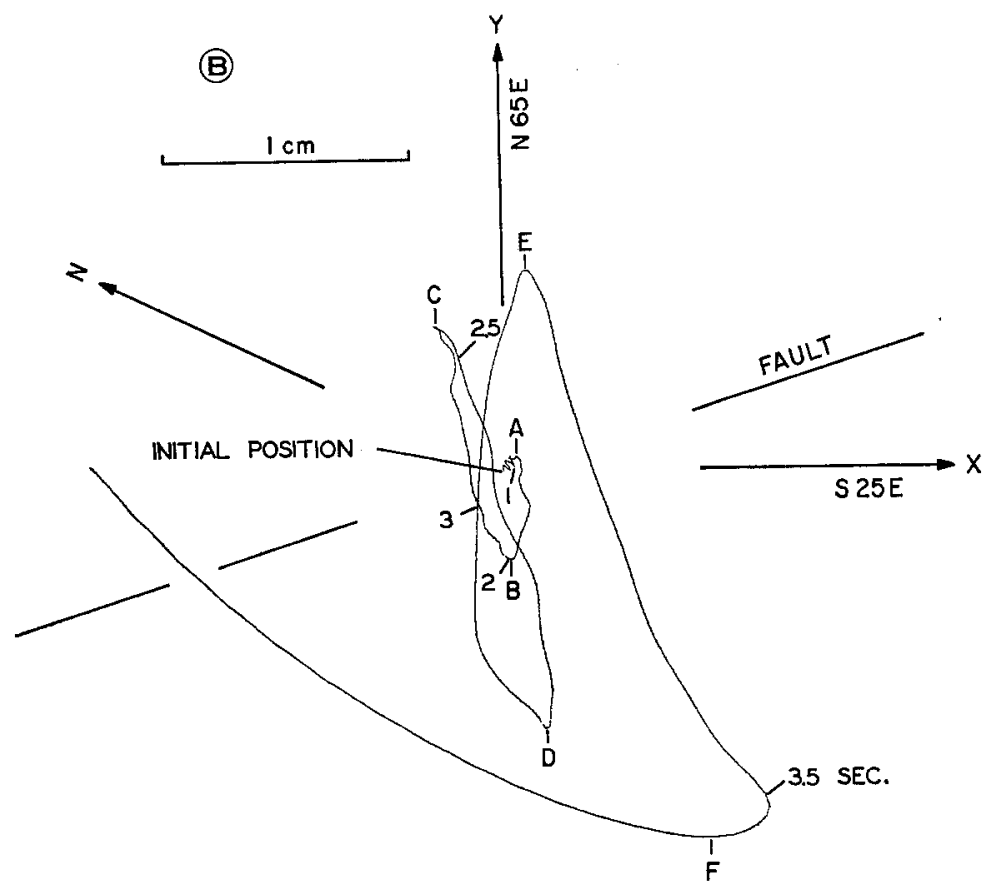

FIG. 5b. Plot of the digitized seismoscope record at Station 2 after the functions $\varphi(t)$ and $\psi(t)$ have been smoothed. The letters A, B, . . identify peak points whose time coordinates are also indicated in Figures 4 and 6.

the recorded seismoscope response in the direction of the calculated response then appears as in Figure 4. Although the recorded and calculated amplitudes are not identical their agreement is remarkable. The letters A, B, $\cdots$ identify corresponding points in the time response and the smoothed seismoscope record of Figure $5 \mathrm{~b}$.

The problem of deriving the unknown acceleration component by using the seismoscope response is solved when $\psi(t)$ and $\varphi(t)$ are known as functions of time. Equation (1a) then gives $\ddot{x}(t)$ in terms of $\varphi(t)$ and $\ddot{z}(t)$ which are both known. This procedure requires numerical differentiation of $\varphi(t)$ to obtain $\dot{\varphi}(t)$ and $\ddot{\varphi}(t)$. This differentiation can not be performed directly on the $\varphi(t)$ data because of errors during digitization and interpolation. These errors, which are most probably randomly distributed, introduce additional high frequency variations in the $\dot{\varphi}(t)$ and $\ddot{\varphi}(t)$ functions. For this reason, the data defining $\varphi(t)$ are low-pass filtered in order to eliminate this undesirable effect.

The digitized seismoscope record contained 470 data points in the time interval of 
3.8 seconds or some 124 points per second. The points were not uniformly distributed in time but were chosen for an optimum representation of the original record. Equally spaced data points with $\Delta t=.002$ seconds were then generated from the original 470 points by interpolation. These interpolated points were used as an input to the smoothing process which was performed in two steps using simple running mean numerical filters. In the first step, the mean was taken over 10 points and the resulting smoothed data were then again low-pass filtered in a second step averaging 14 points, or equivalently over a 0.028 sec window width. From data smoothed in this way, the final

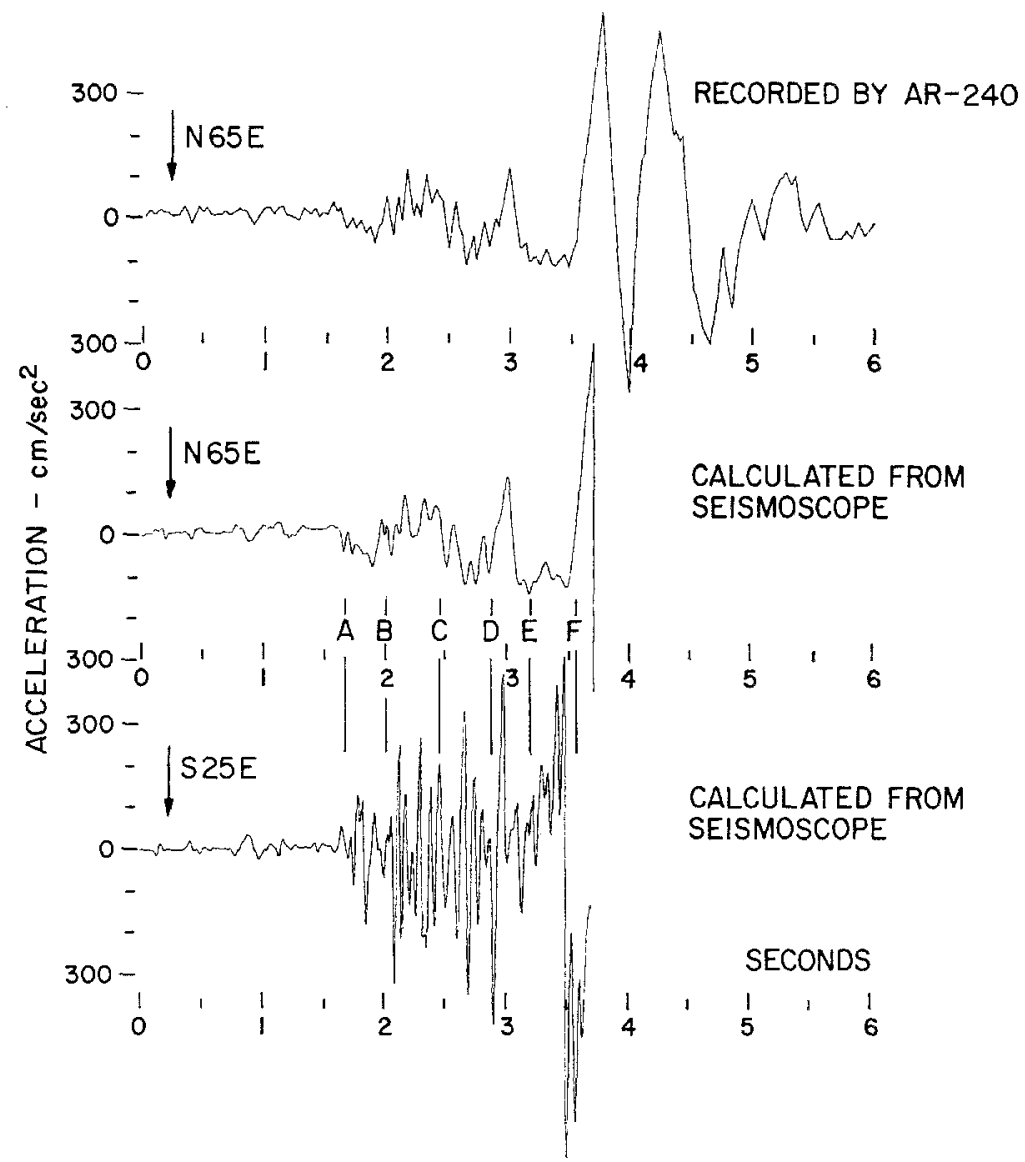

FIG. 6. Comparison of the recorded and derived N65E acceleration component. Bottom trace is the derived $\mathrm{S} 25 \mathrm{E}$ acceleration component. The letters $\mathrm{A}, \mathrm{B}, \cdots$ indicate times of the peaks identified in Figure $5 \mathrm{~b}$.

data were obtained by retaining every tenth point from the original smoothed sequence so that the final time interval became .02 seconds.

The above smoothing procedure is probably adequate for the present purpose as will be seen from the results. No attempt was made to design other filter forms, for example sharp or gradual cut-off low-pass filters. The effect of the above smoothing process is that frequencies greater than approximately $30 \mathrm{cps}$ are filtered out.

In the final calculation of the unknown acceleration component, a further simplification was made in that the fraction of critical damping, $\zeta=8.5$ per cent, was taken as a constant throughout the calculation. In addition, the effect of the vertical acceleration was neglected. These simplifications are justified in the present stage of the 
analysis in view of the preceding data processing steps. The derivatives of the smoothed $\varphi(t)$ and $\psi(t)$ functions were computed by the well known central difference scheme.

The final result of this analysis is given in Figure 6 . The uppermost trace shows the recorded acceleration in the $\mathrm{N65E}$ direction as it was digitized from the accelerograph record. The middle trace shows the same acceleration component as calculated from the seismoscope record by the above procedure. These two traces indicate the degree of agreement that can be achieved by such a procedure. The bottom trace shows the acceleration in the direction parallel to the fault as calculated from the seismoscope record up to 3.8 seconds from the time when the strong motion instrument was triggered. This is the missing trace the reconstruction of which is the object of our investigation.

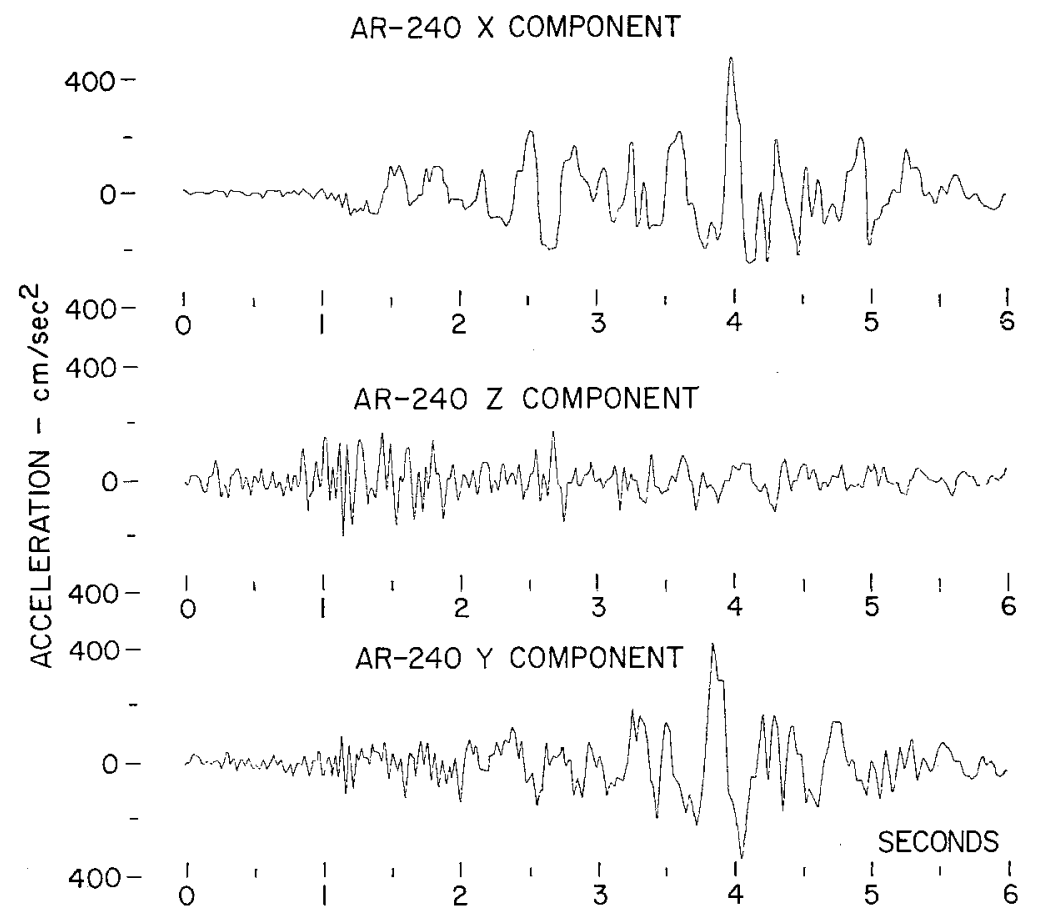

FIG. 7. Plot of the three acceleration components used for the test of the mathematical seismoscope model.

\section{Analysis of a Mathematical Seismoscope Model}

Since the computation methods used above involve essentially a double differentiation process, the agreement between the measured and calculated acceleration curves in Figure 6 is remarkable. In view of the many simplifying assumptions which were made in the course of the analysis, the overall agreement may well be thought to be surprising.

To throw additional light on the accuracy of such methods it was thought desirable to work out another case. For this purpose an artificial computer constructed seismoscope record was made, corresponding to a recorded earthquake ground motion for which all three acceleration components were available. The above analysis process was applied to this artificial seismoscope record and one of the horizontal components. The other horizontal component was then calculated and could be compared directly 
with the known record. In this way an overall check of the entire process is obtained. In view of the fact that some of the simplifying assumptions such as that of small motions are difficult to individually justify, such an additional overall check was deemed desirable.

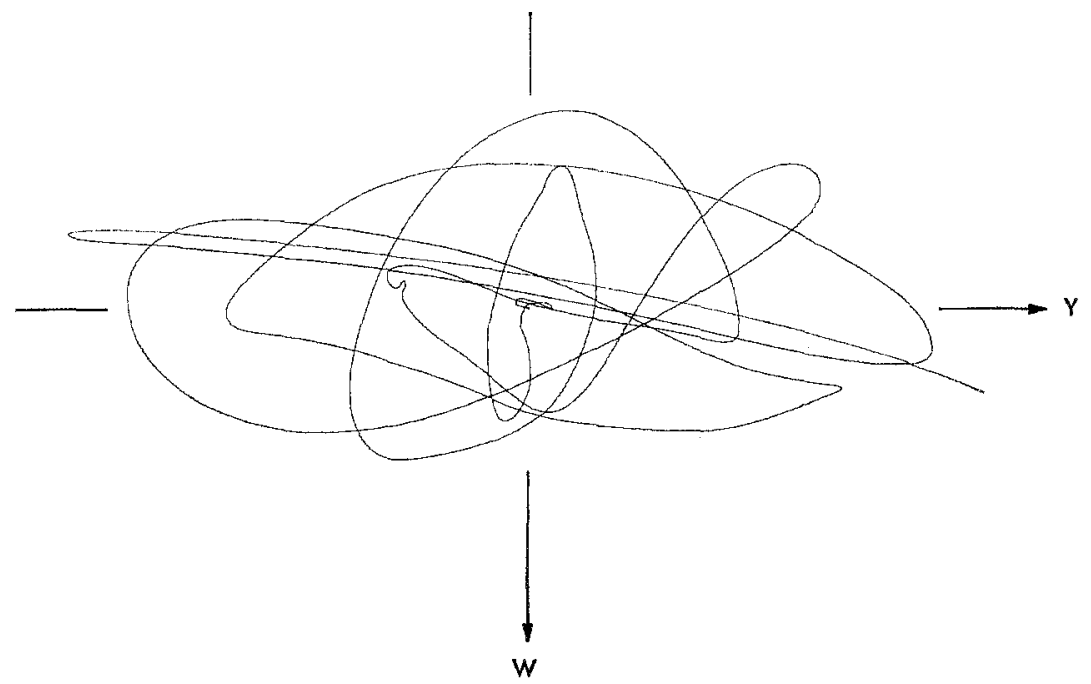

Frg. 8. Computer generated seismoscope record.

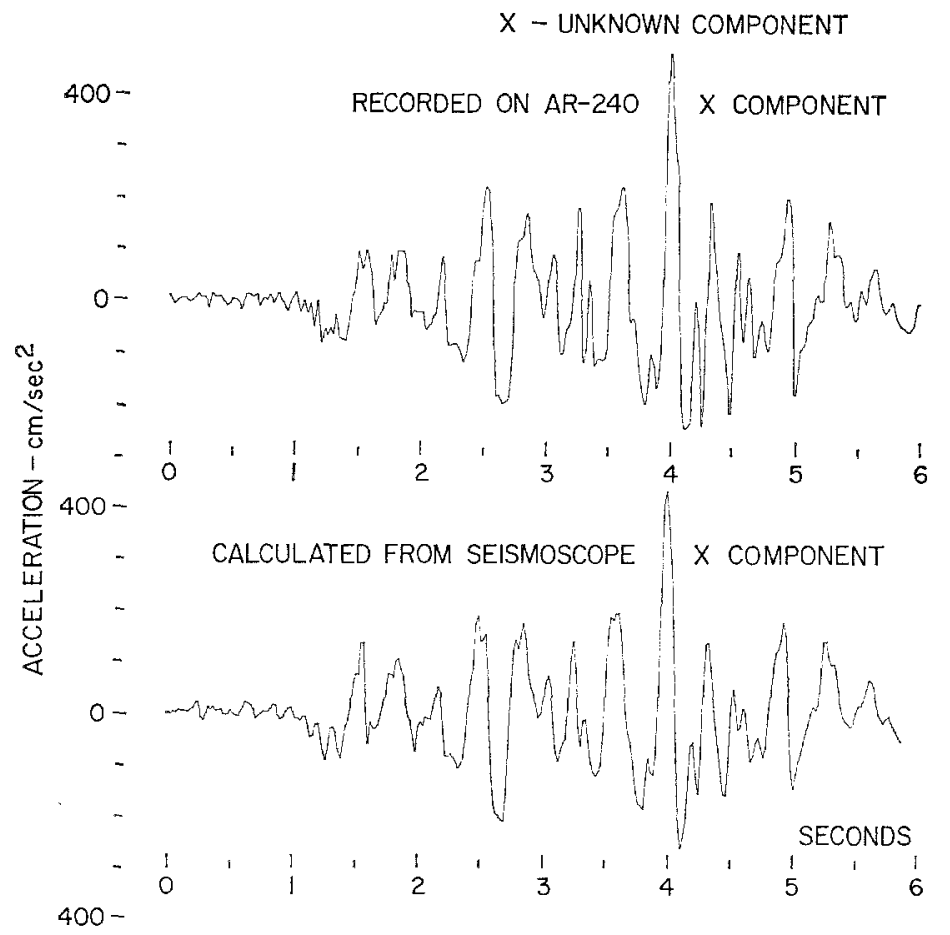

Fig. 9. Comparison of the recorded and derived $x$ - "unknown" component for the mathematical seismoscope model.

Figure 7 is a plot of the three digital accelerograph components for the test earthquake. Equations (1) were integrated simultaneously for this earthquake thus yielding the "artificial" seismoscope record on Figure 8. It was then assumed that the $x$-component of the accelerogram of Figure 7 was unknown. The process described above 


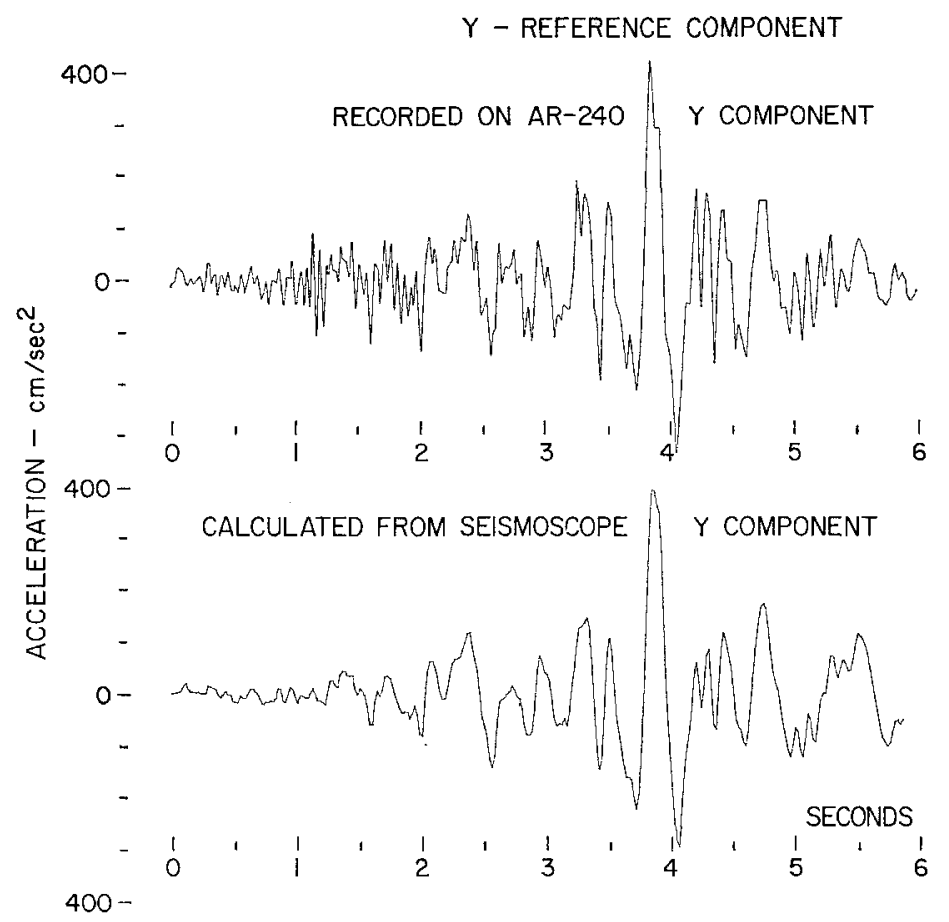

FIG. 10. Comparison of the recorded and derived $y$-known component for the mathematical seismoscope model.

was then used to construct the unknown $x$-component from the given $y$-component and the seismoscope record. The comparison of the calculated $x$-component and the original is shown in Figure 9. The agreement is seen to be of the same general quality as that shown in Figure 6 for the Parkfield earthquake. A comparison of the $y$-component is give in Figure 10, in which it will be seen that the smoothing process has eliminated some of the higher frequency components.

\section{The Character of the Ground Motion at Station 2}

Referring to Figure 6, the most striking feature of the reconstructed S25E direction of ground acceleration parallel to the fault is the relatively high frequency content as compared with the transverse direction. Such high frequency components could not be a consequence of the data handling techniques which are inherently smoothing processes. The final smoothed $\varphi(t)$ function is given by equally spaced data points with $\Delta t=.02$ seconds. The corresponding Nyquist frequency would be $25 \mathrm{cps}$ which is significantly higher than the predominent high frequency content of the $\mathrm{S} 25 \mathrm{E}$ component which is about $15 \mathrm{cps}$.

The marked difference in the frequency content of the two horizontal components at Station 2 is a new feature which has not been observed on any other recorded strong motion accelerograph records. There have been, of course, no other records from instruments so close to the fault. All of the other stations in the array which were located at greater distances showed "normal" type frequency content, being essentially the same for the two horizontal components (Cloud and Perez, 1967; Housner and Trifunac, 1967). The vertical components, however, customarily contain higher frequencies than the horizontal components, as may also be seen from the records of the other array stations (Cloud and Perez, 1967; Housner and Trifunac, 1967).

The special configuration at Station 2 is of course different from that of any past 
recorded earthquake and there is thus no reason to be surprised at new patterns. It is also worthy of note that the peak acceleration during the first 3.8 seconds is apparently about 20-30 per cent higher for the $\mathrm{S} 25 \mathrm{E}$ component along the fault than for the transverse component. Since this $\mathrm{S} 25 \mathrm{E}$ record is known for only 3.8 seconds, it would not be feasible to attempt a displacement-time calculation, which would be subject to a considerable uncertainty as to base-line location.

\section{Conclusions}

The analysis of the seismoscope record at Station 2 recorded during the 1966 earthquake at Parkfield, California, resulted in useful additional information about the earthquake and about the seismoscope. Some of the major findings are:

(1) The character of the derived $\mathrm{S} 25 \mathrm{E}$ component of the ground acceleration is different from past recorded strong earthquake ground motions in that higher frequency components are present. It is the first ground acceleration recorded essentially at the causative fault in the direction parallel to the fault.

(2) The analysis of the seismoscope record at Station 2 indicates that the peak accelerations during the first 3.8 seconds in both directions perpendicular and parallel to the fault were of the same order of magnitude and were about 50 per cent of gravity.

(3) If used in conjunction with at least one component of a measured ground motion, the relatively simple and inexpensive seismoscope instrument may give valuable information beyond the original intentions with which this instrument was designed.

(4) Simple smoothing procedures can be effectively used in the data processing of other records of strong earthquake ground motion whenever differentiation of the digitized data is required.

\section{ACKNOWLEDGMENTS}

Thanks are expressed to the California State Department of Water Resources and the U. S. Coast and Geodetic Survey for making available the data on the Parkfield earthquake. We are indebted to David P. Hentchel for assistance in data processing. The work was carried out under a grant from the Engineering Division of the National Science Foundation.

\section{REFERENCES}

Cloud, W. K. and D. E. Hudson (1961), A simplified instrument for recording strong motion earthquakes, Bull. Seism. Soc. Am. 51, 159-174.

Cloud, W. K. (1966). Preliminary Engineering Seismological Report-The Parkfield, California Earthquake of June 27, 1966. U. S. Department of Commerce, Coast and Geodetic Survey.

Cloud, W. K. (1967). Intensity map and structural damage, Parkfield, California earthquake of June 27, 1966, Bull. Seism. Soc. Am. 57, 1161-1178.

Cloud, W. K. and V. Perez (1967). Accelerograms-Parkfield earthquake, Bull. Seism. Soc. Am. 57.

Housner, G. W. and M. D. Trifunac (1967). Analysis of accelerograms-Parkfield earthquake, Bull. Seism. Soc. Am. 57, 1193-1220.

Hudson, D. E. (1958). The Wilmont Survey Type Strong-Motion Earthquake Recorder, Earthquake Engineering Research Laboratory, California Institute of Technology.

Hudson, D. E. and W. K. Cloud (1967). Analysis of seismoscope data from Parkfield earthquake of June 27, 1966, Bull. Seism. Soc. Am. 57, 1143-1159.

Division of Engineering and Applied Science

California Institute of Technology

Pasadena, California

Manuscript received September 1, 1969 